\title{
Repair of ventricular septal defect and left ventricular aneurysm following myocardial infarction
}

\author{
Z. SCHLESINGER, ${ }^{1}$ Y. LIEBERMAN,A. LANDESBERG, and \\ H. N. NEUFELD \\ The Heart Institute and Department of Thoracic Surgery, Tel-Hashomer Government Hospital, \\ University of Tel-Aviv Medical School, Israel
}

\begin{abstract}
A successful simultaneous surgical repair of rupture of the interventricular septum and left ventricular aneurysm resulting from myocardial infarction is described. Very few similar cases have been described in the literature and in none was angiocardiography performed before operation. Preoperative angiocardiographic examination to demonstrate a ventricular aneurysm is of major importance in all cases of rupture of the interventricular septum following myocardial infarction. The right heart approach with injection of contrast material into the main pulmonary artery is shown to be the method of choice for this purpose.
\end{abstract}

The association of rupture of the interventricular septum with ventricular aneurysm in patients following myocardial infarction is a highly lethal complication. Complete surgical correction of these anomalies may be a life-saving procedure. However, in the reviewed literature there have been only few reported attempts to repair both rupture of the interventricular septum and ventricular aneurysm (Collis, Raison, Mackinnon, and Whittaker, 1962; Taylor, Citron, Robicsek, and Sanger, 1965; Green, Oakley, Davies, and Cleland, 1965; Heimbecker, Chen, Hamilton, and Murray, 1967; Daicoff and Rhodes, 1968; Selzer, Gerbode, and Kerth, 1969; Stinson, Becker, and Shumway, 1969; Limsuwan, Glass, and Jacobs, 1970; Daggett, Burwell, Lawson, and Austen, 1970). Furthermore, in none of the described cases was angiocardiography performed before the operation in order to demonstrate the ventricular aneurysm. The purpose of this paper is: (1) to report our experience of a successful simultaneous surgical repair of rupture of the interventricular septum and left ventricular aneurysm resulting from myocardial infarction in an elderly woman, and (2) to stress the importance and advantages of combining an angiocardiographic examination with preoperative right heart catheterization in such cases.

\section{CASE REPORT}

A 70-year-old woman was admitted to hospital on 18 December, 1969, as an emergency case because of severe chest pains. The clinical diagnosis of acute myocardial infarction was confirmed by high levels of blood enzymes (serum aspartate aminotransferase and lactate dehydrogerase) and electrocardiographic evidence of acute myocardial infarction in the anterior wall. Careful mobilization of the patient was started on 7 January, 1970. On 11 January, severe chest pain reappeared together with sweating and shortness of breath. At that time a pansystolic murmur grade 3/6 with maximal intensity at the lower left sternal border, radiating to the right, was heard for the first time. After that her condition deteriorated markedly and signs and symptoms of left and right heart failure persisted despite intensive treatment with digitalis and diuretics. After failure to improve over a three-month period she was transferred to our ward for further investigations.

Her complaints at the time of admission were severe fatigability and shortness of breath even with the mildest physical effort such as dressing and combing her hair. Physical examination revealed a woman in poor general condition. The cervical veins were engorged, the liver was palpable $6 \mathrm{~cm}$ below the right costal margin, slight pitting oedema was present in the lower extremities, and wet crepitations could be heard at both lung bases. Blood pressure was $130 / 100$ mmHg. Examination of the heart showed a wide apical uplift with paradoxical pulsation in this region. No change was noted in the systolic murmur previously described. The electrocardiogram showed sinus rhythm and was compatible with an anteroseptal wall aneurysm. The chest radiograph showed increased pulmonary vascularity, cardiac enlargement, and ventricular aneurysm (Fig. 1A). Fluoroscopy revealed paradoxical pulsation of the aneurysmal region. $A$ tall ' $A$ '

'Reprint requests: Z. Schlesinger, M.D., Heart Institute, TelHashomer Government Hospital, Israel 

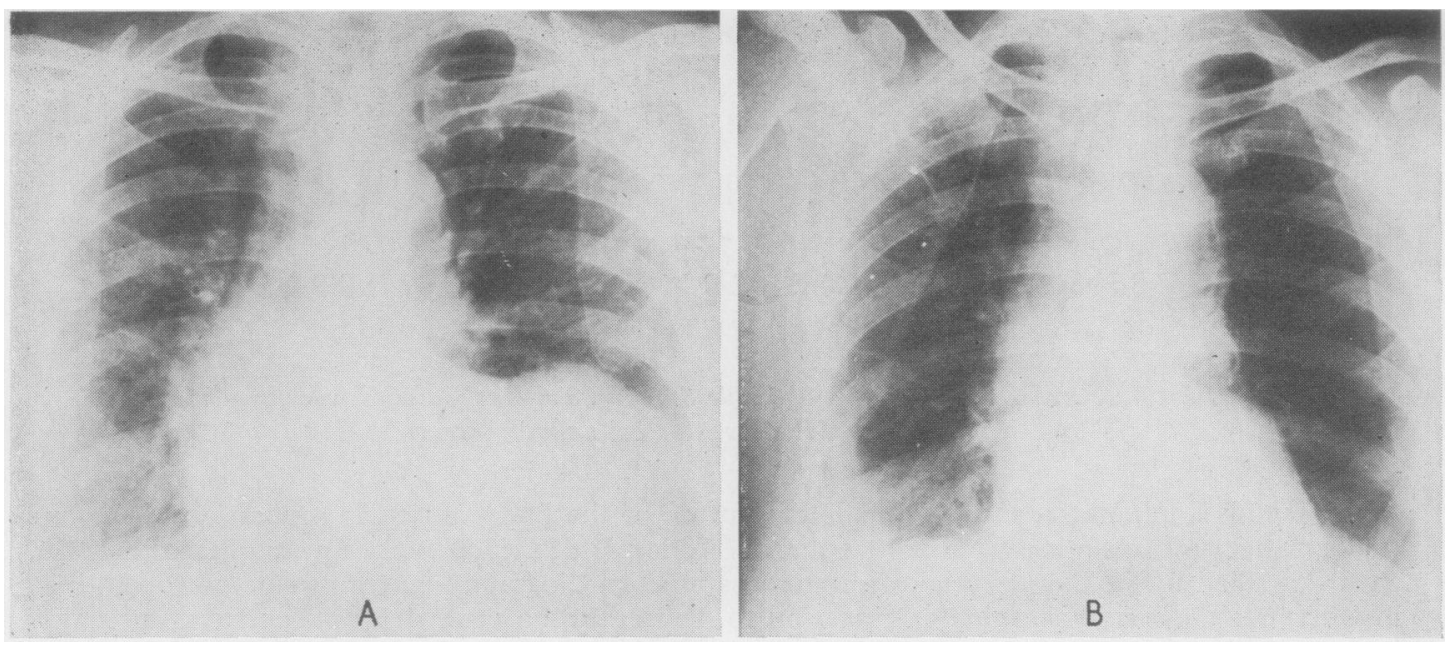

FIG. 1. Radiographs $(A)$ before operation and $(B)$ four weeks after operation.

wave was recorded on the apex-cardiogram and the ratio of this ' $A$ ' wave to the total height of the apexcardiogram tracing, measured from the $\mathrm{E}$ point to the O point, was $32 \%$ (the upper normal limits are considered to be $20 \%$ ) (McGinn, Gould, and Lyon, 1968). The ejection phase of the curve was distorted by a 'systolic bulging'. The carotid pulse was indicative of a prolonged 'left ventricular ejection time index' (Weissler, Harris, and White, 1963) of 0.42 second. Right heart catheterization carried out on 6 May, 1970, revealed a left-to-right shunt at the ventricular level. The ratio of pulmonary blood flow to systemic $\vec{\varphi}$ blood flow was $2 \cdot 7$ to $1 \cdot 0$; the systolic pressure in the : right ventricle and main pulmonary arteries was similarly raised. The pressure in the main pulmonary artery was $50 / 18 \mathrm{mmHg}$ with a mean of $30 \mathrm{mmHg}$. Angiocardiography with injection of contrast material into the main pulmonary artery showed increased pulmonary vascularity and an enlarged left atrium which was displaced toward the right (Fig. 2). The opacification of the left ventricle revealed a large aneurysm located in the upper lateral portion of the enlarged left ventricle
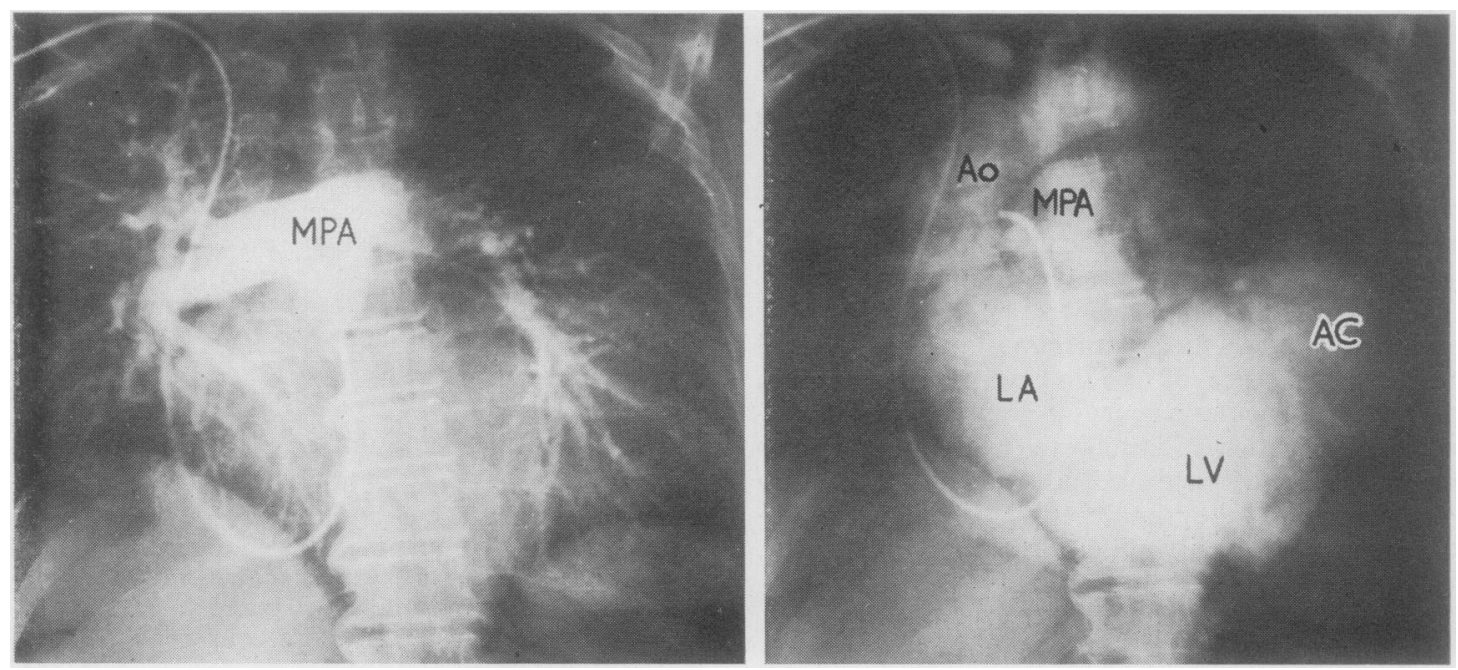

FIG. 2. Preoperative angiocardiogram. The contrast material is injected into the main pulmonary artery. MPA-main pulmonary artery; Ao-aorta; LA-left atrium; LV-left ventricle; AC-aneurysmal cavity. 
(Fig. 2). The ascending aorta and main pulmonary artery were simultaneously opacified through the left ventricle (Fig. 2).

On 10 May, the patient was operated upon. An aneurysm, $8 \mathrm{~cm}$ in diameter and partly obstructed by an organized thrombus, was removed and a rupture of the interventricular septum located at the apical and anterior septum, measuring approximately $0.9 \mathrm{~cm}$ in diameter, was repaired by suture. The perfusion lasted 25 minutes. The operative and postoperative courses were uneventful. The postoperative chest radiograph showed marked diminution of the heart silhouette compared to the preoperative one (Fig. 1B). The postoperative electrocardiographic tracing showed old anteroseptal wall infarction without evidence of ventricular aneurysm.

The patient was discharged from hospital three weeks after operation in excellent condition. However, she was readmitted four months after the operation because of acute myocardial infarction in the inferior wall. This hospitalization lasted four weeks and was uncomplicated. The patient has now been followed at our outpatient clinic for nine months (after the operation) and despite the recent event she is active and feels well. On treatment with digitalis and mild diuretics she is completely free of signs of congestive heart failure.

\section{DISCUSSION}

A review of the literature discloses that the ages of the patients with ruptured interventricular septum and concomitant ventricular aneurysm who underwent surgical repair ranged from 47 to 76 years with the exception of a 10-year-old boy whose myocardial infarction was due to a deep indirect injury (Green et al., 1965). All the patients except one (Limsuwan et al., 1970) were men. Right heart catheterization which revealed a leftto-right shunt at the ventricular level was performed in most of the patients before surgical correction. However, in none of the described cases was the ventricular aneurysm demonstrated by angiocardiography before operation. Furthermore, in some of the described cases the ventricular aneurysm was an accidental finding during operation for closure of a rupture of the interventricular septum. The presence of a ventricular aneurysm may be difficult to ascertain clinically preoperatively, since the symptoms and findings of rupture of the interventricular septum predominate. In addition, the ventricular aneurysm may also be overlooked at operation because of adhesions. The presence of a rupture of the interventricular septum should raise suspicion regarding the existence of a ventricular aneurysm, since the incidence of ventricular aneurysm in patients who had undergone surgical repair of ruptured interventricular septum was more than $30 \%$ according to Daicoff and Rhodes (1968). Preoperative angiocardiographic examination in cases of rupture of the interventricular septum to determine the site and size of the ventricular aneurysm is therefore of major importance for the cardiologist and the thoracic surgeon. It is our opinion that for this purpose injection of contrast material into the main pulmonary artery is preferable to direct left ventriculography by the retrograde approach for the following reasons :

(1) Complications of direct left ventriculography (Beckmann and Dooley, 1970), such as acute rhythm disturbances, acute left heart failure, and embolic phenomena originating from aneurysmal thrombi, may be avoided.

(2) The injection of contrast material into the main pulmonary artery in the course of right heart catheterization saves another procedure. Right heart catheterization is obligatory in these cases in order to evaluate the degree of left-to-right shunt and the pulmonary resistance.

(3) According to our experience (Schlesinger, Lieberman, and Neufeld, 1971), the degree of radiological opacification of the aneurysmal cavity obtained by the right approach is very satisfactory.

\section{REFERENCES}

Beckmann, C. H., and Dooley, B. (1970). Complications of left heart angiography. A study of 1,000 consecutive cases. Circulation, 41, 825.

Collis, J. L., Raison, J. C. A., Mackinnon, J., and Whittaker, S. R. F. (1962). Repair of acquired interventricular septal defect following myocardial infarction. Lancet, 2, 172.

Daggett, W. M., Burwell, L. R., Lawson, D. W., and Austen, W. G. (1970). Resection of acute ventricular aneurysm and ruptured interventricular septum after myocardial infarction. New Engl. J. Med., 283, 1507.

Daicoff, G. R., and Rhodes, M. L. (1968). Surgical repair of ventricular septal rupture and ventricular aneurysm. J. Amer. med. Ass., 203, 457.

Green, L:, Oakley, C. M., Davies, D. M., and Cleland, W. P. (1965). Successful repair of left ventricular aneurysm and ventricular septal defect after indirect injury. Lancet, 2, 984.

Heimbecker, R. O., Chen, C., Hamilton, N., and Murray, D. W. G. (1967). Surgery for massive myocardial infarction. An experimental study of emergency infarctectomy. Surgery, 61, 51.

Limsuwan, A., Glass, B. A., and Jacobs, S. (1970). Ventricular septal defect and ventricular aneurysm following myocardial infarction. Chest, 57, 581.

McGinn, F. X., Gould, L., and Lyon, A. F. (1968). The phonocardiogram and apexcardiogram in patients with ventricular aneurysm. Amer. J. Cardiol., 21, 467.

Schlesinger, Z., Lieberman, Y., and Neufeld, H. N. (1971). Ventricular aneurysmectomy for severe rhythm disturbances. J. thorac. cardiovasc. Surg., In press. 
Selzer, A., Gerbode, F., and Kerth, W. J. (1969). Clinical, hemodynamic, and surgical considerations of rupture of the ventricular septum after myocardial infarction. Amer. Heart J., 78, 598.

Stinson, E. B., Becker, J., and Shumway, N. E. (1969). Successful repair of post-infarction ventricular septal defect and biventricular aneurysm. J. thorac. cardiovasc. Surg., 58, 20.

Taylor, F. H., Citron, D. S., Robicsek, F., and Sanger, P. W. (1965). Simultaneous repair of ventricular septal defect and left ventricular aneurysm following myocardial infarction. Ann. thorac. Surg., 1, 72.

Weissler, A. M., Harris, L. C., and White, G. D. (1963). Left ventricular ejection time index in man. $J$. appl. Physiol., 18, 919.

\section{ADDENDUM}

Another patient, a man aged 61 years, was operated upon on 31 March, 1971. A simultaneous repair of rupture of the interventricular septum and left ventricular aneurysm was performed $17 \frac{\mathrm{\sigma}}{\mathrm{C}}$ days after the onset of acute anterior wall myo-듬 cardial infarction. A pansystolic murmur grade $\overline{\bar{\sigma}}$ $3 / 6$ with maximal intensity at the lower left $\overparen{\otimes}$ sternal border was noted on the sixth day after the acute episode and the patient developed severe congestive heart failure with repeated attacks of $\overrightarrow{0}$ ventricular tachycardia. Right heart catheterization $\vec{二}$ and angiocardiography with injection of contrast material into the main pulmonary artery was carried out two weeks after the acute episode. The studies indicated raised pressure in the main pul-? monary artery, left-to-right shunt at the ventri-or cular level, and an aneurysmal dilatation of the $\frac{G}{G}$ anterolateral portion of the left ventricle. The o postoperative course was uneventful. At present, $\underset{ }{\supset}$ 10 weeks after surgery, the patient has no rhythm $\overrightarrow{c s}$ disturbances and on digitalis and diuretics he is $\mathbb{D}$ free of congestive heart failure. 